\title{
The Moderating Effect of Local VS. Foreign Courier Service Providers on Logistic Service Quality (LSQ)
}

\author{
Jessica Sze Yin Ho, Derek Ong Lai Teik, Felicia Tiffany, Loong Fatt Kok, and Tat Yang Teh
}

\begin{abstract}
In the courier services industry, service quality is among the most crucial factors for customer satisfaction. This paper applies the Logistic Service Quality (LSQ) model, using variables which include 'timeliness', 'condition/accuracy of order', 'quality of information', and 'availability/quality of personnel' in determining the most effective dimension for providing sound service quality to achieve customer satisfaction under the current market conditions. Multiple regression analysis based on 200 respondents indicated that 'timeliness' has been replaced by 'condition/accuracy of order' as the priority for courier services' customers. The impact of the shift from 'timeliness' to 'condition/accuracy of order' and areas to cover in the future are discussed. Additionally, this paper also explored the moderation effect of foreign and local logistics service providers in influencing the relationship between LSQ and customer satisfaction. Findings show that LSQ perceptions were different for local and foreign companies. This difference in LSQ perceptions eventually affects customer satisfaction.
\end{abstract}

Index Terms-Logistic Service Quality (LSQ), Customer Satisfaction, Courier Services.

\section{INTRODUCTION}

In past decades, logistics has always been a supporting function for production and consumption. For traditional courier service companies the only function that was considered was cost. However, since the 1990s, this perception has started to change due to the marketing principle of determining the capacity of the courier service which has lead to greater customer satisfaction and loyalty [1]. The courier services industry in Malaysia is beginning to experience mounting competition as more courier logistic companies (local and foreign) have been set up. Unfortunately, little information is available to pinpoint country specific areas of customer satisfaction concerns between courier service providers. Hence, this paper aims to determine the service quality dimensions that influence customer satisfaction in the courier service industry focusing on quality: (1) timeliness; (2) condition/accuracy of order; (3) quality of information; and (4) availability/quality of information. In addition to evaluating the service quality among logistics service providers, this study is also motivated by the notion suggested in past studies by Javalgi, Cutler and Winans (2001) and Stanton and Veale (2009), where country of origin (COO) of the service provider is believed to influence customers' quality perception [2], [3]. Hence, this study also explores the moderation effect of local

Manuscript received June 2, 2012; revised July 15, 2012.

The authors are with Sunway University Business School, No. 5, Jalan Universiti, Bandar Sunway, 46150 Petaling Jaya, Selangor, Malaysia. (e-mail: jessicah@sunway.edu.my) versus foreign logistics service providers.

\section{THEORETICAL BACKGROUND AND HYPOTHESIS}

In the service industry, customer satisfaction is a vital element which contributes heavily to customer loyalty $[4,5]$. Customer satisfaction that increases customer loyalty eventually leads to business profitability. Parasuraman (2004) defines customer satisfaction as a "result" of the "comparison between predicted service and perceived service" while service quality refers to the "comparison between desired service and perceived service" [6]. An instrument that is applicable for measuring service quality is the SERVQUAL model. According to Mentzer, Flint, and Hult (2001), SERVQUAL can be considered an effective "analytic instrument in evaluating and monitoring service quality" [1]. This paper employs Logistic Service Quality (LSQ), which has gone through modification during the development of logistic traits that fits into prior consumer-based scopes and identifies potential improvements [1]. Mentzer, Flint, and Hult (2001) also suggested that firms are required to pay attention to their own marketing efforts as well as the physical distribution service (PDS), as these elements are key to achieving customer satisfaction and put forward a unified framework of customer service [1].

Based on the customer value theory, timeliness is one of the essential elements in the relationship between logistic provider and customers [7]. Timeliness refers to whether orders that have been placed are delivered on time as promised [5]. It is essential as it helps in reducing the overall operation process in terms of times between service stops [8]. It has been found that customer satisfaction can be further enhanced given the availability of flexible timeliness based on demand [9]. Based on the above rationale, the following hypothesis is derived:

H1: Timeliness has a significant influence on customer satisfaction with courier services.

According to $\mathrm{Xu}$ and $\mathrm{Cao}$ (2008), this variable measures the average effectiveness and success of a courier provider once they have received a customers' order [10]. It also involves the accuracy of billing and record keeping as well as the completion of the service at the designated time [6]. Furthermore, it is important for firms to meet the demands stated in a particular order in terms of quantity and quality upon arrival, in terms of whether or not the package sustained any damage [1],[5]. Should any complaints be made and then mismanaged, it would lead to customer dissatisfaction and further prompt a switch to a competitor from the industry [1]. Based on the above rationale, the following hypothesis is 
derived:

H2: Condition/accuracy of order has a significant influence on customer satisfaction with courier services.

The ability of courier providers to include relevant product information is essential to attract customers' attention to their specific service and promotions that meet their needs $[5,7]$. Overall customer satisfaction can be affected by the information provided, in terms of trustworthiness and quality of information, which can help customers make better decisions [1]. Parasumaran (2004) suggested that firms should consider providing information in multiple languages [6], which is relevant to the area of study for this paper, Malaysia, where there are three main races (Malays, Chinese and Indians). Based on the above rationale, the following hypothesis is derived:Based on the above rationale, the following hypothesis is derived:

H3: Quality of information has a significant influence on customer satisfaction with courier services.

Sound interaction between personnel and customers has been discussed as being a factor contributing to customer satisfaction [10]. The ability of personnel to distinguish regular clients is equally important as learning individual preferences, problem solving and improving knowledge of products, as well as providing customised attention that will increase satisfaction and in return encourage future repurchases [11]. Lu, Tu and Jen (2011) brought forward the idea of switching barriers in addition to personnel competence as a pair in a model examining behavioural intentions when addressing the possibility of a customer switching to a competitor as mentioned above [11].

H4: Availability/quality of personnel has a significant influence on customer satisfaction with courier services.

Our study will be based on the SERVQUAL model [6] as it fits the area of interest, which is the service quality that the courier industry provides. The model also includes the difference between perceived and expected quality. However, for this paper, some modifications were needed to produce more comprehensive research. Thus, the LSQ model by Collier and Bienstock (2006), which includes an extra 4 dimensions that are represented by our independent variables, was adapted [12]. The LSQ model has also been utilised by other researchers including Saura, Fraces, Contri, and Blasco (2008), from which we developed our questionnaire [5].There has been very limited incorporation of the LSQ in studies conducted in Malaysia, thus this paper will further test whether the model is applicable or not (see Fig. 1).

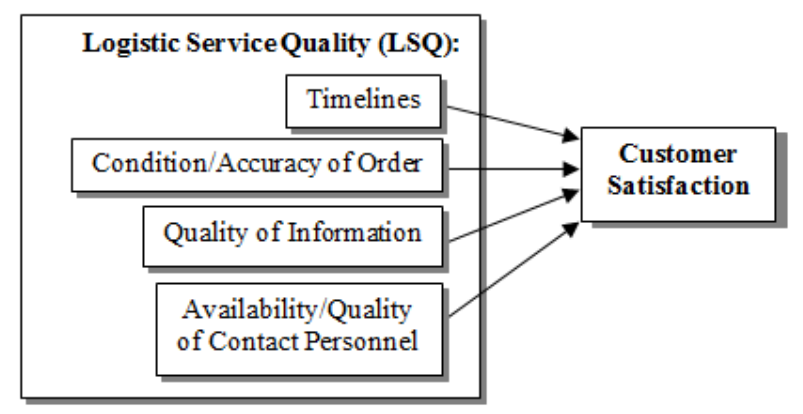

Fig. 1. Research Framework

The lucrative market of logistic servicing, as a result of borderless trading, has attracted many foreign companies to expand into developing countries [2]. When a foreign service provider enters a new market, it is common for the foreign service provider to transfer the service culture from their home country, to differentiate their service culture and service quality from their local counterparts with minimal localization [13]. Studies on COO that elucidate how the impression of a product or service from the source country affects consumers' quality perceptions [3] can be used to explain the differences in perceived service quality between local and foreign companies. Stanton and Veale (2009) added that it was possible for $\mathrm{COO}$ to infer the quality of service offered due to the nature of the service, where it is possible for information about services to be ambiguous [3]. Although there were limited studies investigating the effect of $\mathrm{COO}$ on logistics service preferences, a recent study conducted in the Asian context (China) found that customers prefer foreign logistics service providers due to more advanced management, better service quality, and better equipment and facilities [14]. Past studies in regards to country of origin of service providers, however, have not evaluated the possibility of the moderating effect of $\mathrm{COO}$, in this case, local and foreign LSQ on customer satisfaction. Based on the above rationale, the following hypothesis is derived:

H5: Local and foreign logistics service providers moderate the relationship between each $L S$ ) variable and customer satisfaction.

\section{Methodology}

The 35 item questionnaire adapted for this study employs a four-point Likert scale, with anchors ranging from 'strongly disagree' to 'strongly agree', that was chosen as it helps in eliminating the 'neither/nor' position, as it was found that without such a position respondents have the tendency to choose from a negative scale which helps in getting a more accurate set of responses [15]. The unit of analysis for this study are individuals pursuing their studies in higher educational institutions in Malaysia. Online media, including personal emails and online survey platform 'Survey Monkey', was used in obtaining data. Snowball sampling was chosen when conducting our sampling method as it allows us to identify respondents who have the specific range of characteristics that are useful for the research [16]. To qualify as a respondent for this study, respondents must have used any courier services in the last year. Through this method, a total of 200 usable questionnaires were obtained out of 203 questionnaires collected.

\section{ANALYSIS AND RESUltS}

\section{A. Respondents Demographic Profiles}

The respondents of this study were 51\% female and $49 \%$ male. The majority of the respondent were students (71\%), while the rest were employed (29\%). As the study focuses on courier services provided in Malaysia, there were more Malaysian respondents (64.5\%) compare to non-Malaysians who live in Malaysia (35.5\%). A good number of 
respondents were at the undergraduate level (77.5\%), alongside respondents at the diploma level (12\%), postgraduate $(8.5 \%)$, and other levels of education, such as pre-university and A-levels (2.5\%).

\section{B. Final Stage Relationship between LSQ and Customer Satisfaction}

In terms of preferences and satisfaction of the respondents for a specific courier services provider, out of 200 respondents, $41 \%$ of respondents chose Pos Laju as their preferred provider for courier services (see Table I). Even though Pos Laju was the most popular choice it only achieved a score of 2.95 out of 4 on the Likert Scale in terms of customer satisfaction, which is lower than the satisfaction levels towards FedEx and DHL, which stand at 3.204 and 3.13 out of 4 , respectively. This indicates that customers who experienced the service by FedEx had the highest level of satisfaction in comparison to the other providers.

TABLE I: MEAN OF CUSTOMER SATISFACTION WITH DIFFERENT COURIER SERVICE PROVIDERS

\begin{tabular}{lcccc}
\hline \hline Courier Service Providers & \multicolumn{2}{c}{ Usage Frequency } & \multicolumn{2}{c}{ Customer Satisfaction } \\
& $\begin{array}{c}\text { Frequency } \\
(\mathrm{n})\end{array}$ & $\begin{array}{c}\text { Percentage } \\
(\%)\end{array}$ & Mean & Stdev \\
\hline Pos Laju (Pos Malaysia) & 81 & 40.5 & 2.9460 & 0.4593 \\
DHL & 57 & 28.5 & 3.1491 & 0.4861 \\
FedEx & 45 & 22.5 & 3.1250 & 0.5119 \\
Others & 17 & 8.5 & 2.9044 & 0.5331 \\
& & & & \\
\hline \hline
\end{tabular}

Note: $\mathrm{N}=200$

All independent variables have substantial relationships and are moderately correlated with the dependent variable (Pearson $r$ ranges from 0.530 to 0.672 , p value $0.000<0.01$ ). Table II shows the relationship between the dependent variable and independent variables obtained from running multiple linear regressions. The F-value of 55.076 (p-value $0.000<0.01$ ) implies that at least one of the variables of the study is significant. Thus, it confirms the fitness of the model [17]. The adjusted $\mathrm{R}$ square is 0.521 , indicating that the model represents $52.1 \%$ of the total variance. An effect of this size, of $52.1 \%$, can be considered to be around the range of a large to very large effect [18].

TABLE II: REGRESSION RESULT

\begin{tabular}{|c|c|c|c|c|c|}
\hline \multicolumn{2}{|l|}{ Variables } & $\begin{array}{c}\text { Beta } \\
\text { Value } \\
\end{array}$ & Sig. & Tolerance & VIF \\
\hline (Constant) & & .425 & $.019 *$ & & \\
\hline Timeliness & & .201 & $.008 *$ & .467 & 2.141 \\
\hline Condition/Accuracy & & & & & \\
\hline of Order & & .321 & $.000^{*}$ & .395 & 2.529 \\
\hline Quality of Information & & .229 & $.002 *$ & .442 & 2.260 \\
\hline $\begin{array}{l}\text { Availability/Quality } \\
\text { of Personnel }\end{array}$ & & .081 & .151 & .562 & 1.780 \\
\hline Multiple R & .728 & & & & \\
\hline $\mathrm{R}^{2}$ & .530 & & & & \\
\hline Adjusted $\mathrm{R}^{2}$ & .521 & & & & \\
\hline$F$ change $=55.076$, Sig. & .000 & & & & \\
\hline
\end{tabular}

Note: $\mathrm{N}=200 ; * \mathrm{p}<0.01$ (2-tailed); Dependent variable: Customer Satisfaction; Independent Variables: Timeliness, Condition/Accuracy of Order, Quality of Information, Availability/Quality of Personnel

Based on the findings, $\mathrm{H} 1$ (timeliness), $\mathrm{H} 2$ (condition/accuracy of order) and H3 (quality of information) are supported with respected p-values of $0.008<0.01(\mathrm{H} 1)$, p-value of $0.000<0.01(\mathrm{H} 2)$ and p-value of $0.002<0.01(\mathrm{H} 3)$. However, H4 (availability/quality of personnel) is rejected with a p-value of $0.151>0.01$, thus deeming it to have no influence on customer satisfaction. In summary, the relationship between the dependent variable (customer satisfaction) and independent variables (timeliness, condition/accuracy of order, and quality of information) are as follows:

$Y=0.425+0.201$ Timeliness +0.321 Condition/Accuracy of Order + 0.229 Quality of Information

The absolute figure shown in Table III represents the beta coefficient of each variable. The result indicates that the independent variables (timeliness, condition/accuracy of order and quality of information) have positive relationships with the dependent variable (customer satisfaction). Furthermore, it can be seen that condition/accuracy of order has the highest beta at 0.326 , which suggests that this variable is the strongest factor in influencing customer satisfaction.

\section{The Moderating Relationship between Local vs. \\ Foreign Courier Service Providers on LSQ and Customer Satisfaction}

As the literature suggested, there are differences in service expectation between $\mathrm{COO}$ of the logistic service providers, this study adapts the COO concept and tests the effect of local versus foreign logistics service providers on each independent variables against customer satisfaction, the variable of service provider was then tested for moderation effect on each single relationship. Service providers were divided into 2 groups from the original 5 groups, in which the local logistic providers comprised of Pos Laju $41 \%(n=81)$ only and foreign logistics service providers comprised of DHL and FedEx, 51\% ( $n=102)$. The remainder were not included in the moderation grouping as the origin of service provider could not be determined. Nevertheless the percentages from the former lists are comparable.

Using the Sobel test for moderation, values of each independent variable were centred (taking mean minus each value) to obtained more accurate results. Then an interaction term, comprising of the product term between the centred values and the moderating variable (logistics service provider; $0=$ local and $1=$ foreign), was created. The centred variable, moderator and the interaction term were all subjected to a hierarchical regression and their unstandardized coefficients were entered into a Sobel test to ascertain the moderation effect.

Table III shows the simple slopes of the moderating groups on each simple regression relationship (one independent variable on customer satisfaction). The analysis also shows that service providers in logistics companies play a part in varying the degree of customer satisfaction as determined by each independent variable of the LSQ. This shows that there are different expectations of logistics service qualities depending on whether the logistics company is a local or a foreign company. This will ultimately determine the differing levels of satisfaction within customers' perceptions. It is interesting to note that steeper slopes were recorded for foreign companies when moderating the relationship 
between timeliness and quality of information, both individually and with customer satisfaction. This phenomenon, however, is true for local companies, when moderating the relationship between condition/accuracy of order and availability/quality of personnel, both individually and with customer satisfaction.

TABLEIII: MODERATION RESULT

\begin{tabular}{|c|c|c|c|}
\hline & Simple Slope & T-Value & Sig. \\
\hline \multicolumn{4}{|c|}{ Customer Satisfaction on Timeliness } \\
\hline Local & 0.446 & 4.986 & $\mathrm{P}<0.01$ \\
\hline Foreign & 0.766 & 9.889 & $\mathrm{P}<0.01$ \\
\hline \multicolumn{4}{|c|}{ Customer Satisfaction on Condition/Accuracy of Order } \\
\hline Local & 0.693 & 8.828 & $\mathrm{P}<0.01$ \\
\hline Foreign & 0.632 & 8.938 & $\mathrm{P}<0.01$ \\
\hline \multicolumn{4}{|c|}{ Customer Satisfaction on Quality of Information } \\
\hline Local & 0.589 & 6.518 & $\mathrm{P}<0.01$ \\
\hline Foreign & 0.661 & 9.348 & $\mathrm{P}<0.01$ \\
\hline \multicolumn{4}{|c|}{ Customer Satisfaction on Availability/Quality of Personnel } \\
\hline Local & 0.361 & 4.661 & $\mathrm{P}<0.01$ \\
\hline Foreign & 0.270 & 3.818 & $\mathrm{P}<0.01$ \\
\hline
\end{tabular}

Note: $\mathrm{N}=183 ; \quad * \mathrm{p}<0.01 \quad$ (2-tailed); Dependent variable: Customer Satisfaction; Independent Variables: Timeliness, Condition/Accuracy of Order, Quality of Information, Availability/Quality of Personnel; Moderating Categories of Logistics Service Providers: Local, Foreign.

\section{DISCUSSION AND CONCLUSION}

This study aimed to examine the aspects of service quality that contribute to customer satisfaction in the logistic service industry of Malaysia. Overall, the results from this study have endorsed previous research, except for the variable of availability/quality of personnel. The main difference in the findings of this paper is that the most significant variable for achieving satisfaction among customers in the courier service industry is the condition/accuracy of order, showing a contrast to previous findings [6], [19], [20] where timeliness was regarded as having the highest level of influence on customer satisfaction. The implication from these two hypotheses ( $\mathrm{H} 1$ and $\mathrm{H} 2)$ suggests that there has been a shift in the trend, and companies should start to recognise this. One feasible explanation for such a shift could be due to customer's trust in their respective choice of courier service provider and such trust can be achieved through matching the timeliness aspect when providing the service [12]. Furthermore, due to increasing expectation from customers, timeliness is seen as an entry-level requirement for every company in the logistic industry [21]. Quality of information was also found to have a strong influence on customer satisfaction for courier services providers (H3). This is in tandem with the results obtained from the study by Dodds (2002), who discussed that "good product information helps to create a more effective market place for both consumers and marketers" [22].

Unlike previous studies, the availability/quality of personnel was not shown to be a factor influencing customer satisfaction for courier service providers (H4). Based on the perspective of customer value theory, the availability/quality of personnel may be viewed as insignificant across the industry in Malaysia; thus, customers are unable to differentiate companies based on this criterion. This is detrimental to the industry in Malaysia as findings have shown that contact personnel are a crucial part in customer satisfaction and upon recognising this factor, companies can provide training needed for their staff to provide better service quality to customers in each branch [5]. Upon the effort of upgrading this, the industry in Malaysia would also improve as a whole and could also be compared to the global level.

Answering the past literature's call for investigation of the influence of $\mathrm{COO}$ on service sectors $[2 ; 3]$, this study found that customers perception of LSQ is indeed different for local versus foreign companies. Results show that local logistic service providers have strengths in delivering accurate orders, making sure that their personnel are available, and providing a good quality of service. Foreign logistics service providers on the other hand provide better quality when it comes to providing timeliness and quality of information to their customers. This is similar to a previous study by Hong, Chin and Lui (2007), where timeliness and quality of information can be attributed to more advanced management, better equipment, and facilities provided by the headquarters of the foreign logistics firms [14]. Hence, it is important for local logistics service providers to invest in improving their management systems, as well as equipment and facilities to keep up with the competition.

This study has several limitations, which suggest avenues for future research. Firstly, due to time and budget constraints, snowball sampling was chosen due to its convenient nature. Future research using a more random method would provide a better representation of samples. Secondly, using university students as the unit of analysis of the study limits the generalizability of this study. Sampling respondents from various groups of respondents including working adults and business organizations might provide a different scope of service quality expectations among logistic service providers.

\section{REFERENCES}

[1] J. T. Mentzer, D. J. Flint, and T. M. Hult, "Logistic Service Quality as a Segment-Customised Process," Journal of Marketing, vol. 64, no. 4, pp. 82-104, 2001.

[2] R. G. Javalgi, B. D. Cutler, and W, A, Winans, "At your Service! Does Country of Origin Research Apply to Service?" Journal of Services Marketing, vol. 15, no. 7, pp. 565-582, 2001.

[3] Stanton, M. and Veale, R. "Decomposing Country of Origin Dimensions of Services: An Investigation into Perceptions of Service Quality in a Transnational Setting," in Proc. ANZMAC 2009 Conf., 2009. [Online]. pp. 1-8. Available: http://anzmac2010.org/proceedings/pdf/anzmac10Final00177.pdf

[4] A. Sharma, D. Grewal, and M. Levy, "The Customer Satisfaction/Logistics Interface," Journal of Business Logistics, vol. 16, no. 2, pp. 1-22, 1995 .

[5] I. G. Saura, D. S. Fraces, G. B. Contri, and M. F. Blasco, "Logistic Service Quality: A New Way to Loyalty," Industrial Management and Data Systems, vol. 108, no. 5, pp. 650-668, 2008.

[6] A. Parasuraman, "Assessing and Improving Service Performance for Maximum Impact: Insights from a Two-Decade-Long Research Journey," Performance Measurement and Metrics, vol. 5, no. 2, pp. 45-52, 2004.

[7] T. Yu, A. E. Ellinger, and C. Haozhe, "Third-party Logistics Provider Customer Orientation and Customer Firm Logistics Improvement in China," International Journal of Physical Distribution \& Logistics Management, vol. 40, no. 5, pp. 356-376, 2010. 
[8] O. M. Choudhry, and A. M. Khan, "Effect of Route Guidance and Route Scheduling Systems on Courier Pickup and Delivery Operations: A Simulation Study," Canada Journal of Civil Engineering, vol. 28, pp. 77-84, 2001.

[9] A. S. Mattila, and D. J. Mount, "The Impact of Timeliness on Complaint Satisfaction in the Context of Call-Centers," Journal of Hospitality and Leisure Marketing, vol. 14, no. 3, pp. 5-16, 2006.

[10] J. Xu, and Z. P. Cao, "Logistics Service Quality Analysis Based on Gray Correlation Method," International Journal of Business and Management, vol. 3, pp. 58-61, 2008.

[11] T. Lu, R. Tu, and W. Jen, "The Role of Service Value and Switching Barriers in an Integrated Model of Behavioural Intentions," Total Quality Management and Business Excellence, vol. 22, no. 10, pp. 1071-1089, 2011.

[12] J. E. Collier, and C. C. Bienstock, "Measuring Service Quality in the E-Retailing," Journal of Service Research, vol. 8, no. 3, pp. 260-275, 2006.

[13] H. T. Hoang, S. R. Jill, and V. N. Lu, "The Influence of Service Culture on Customer Service Quality: Local vs. Foreign Service Firms in Emerging Markets," in Proc. ANZMAC 2010 Conf., 2010. [Online]. pp. $1-9$. Available: http://anzmac2010.org/proceedings/pdf/anzmac10Final00502.pdf

[14] J. Hong, A. T. H. Chin, and B. Liu, "Logistics Service Providers in China - Current Status and Future Prospects," Asia Pacific Journal of Marketing and Logistics, vol. 19, no. 2, pp. 168-181, 2007.

[15] R. Garland, "The Mid-Point on A Rating Scale: Is it Desirable?" Marketing Bulletin, vol. 2, pp. 66-70, 1991.

[16] C. Noy, "Sampling Knowledge: The Hermeneutics of Snowball Sampling in Qualitative Research," International Journal of Social Research Methodology, vol. 11, no. 4, pp. 327-344, 2008.

[17] J. F. Hair, R. E. Anderson, R. L. Tatham, and W. C. Black, Multivariate Data Analysis (5th ed.); Englewood Cliffs: Prentice Hall, 1998.

[18] J. Cohen, "A Power Primer," Psychological Bulletin, vol. 122, pp. 166-159, 1992.

[19] N. Mansor, and C. H. Razali, "Customer's Satisfaction Towards Counter Service of Local Authority in Terengganu Malaysia," Canadian Centre of Science and Education, vol. 6, no. 8, pp. 197-208, 2010.

[20] S. Rahman, "Quality Management in Logistics Practices: A Comparison Between Manufacturing Companies and Logistics Firms in Australia," Total Quality Management, vol. 19, no. 5, pp. 535-550, 2008

[21] P. Kothandaraman, and D. T. Wilson, "The Future of Competition: Value-Creating Networks," Industrial Marketing Management, vol. 30, no. 4, pp. 379-389, 2000

[22] W. B. Dodds, "The Effect of Perceived and Objective Market Cues on Consumers' Products Evaluation," Marketing Bulletin, vol. 13, no. 2, pp. 1-14, 2002.

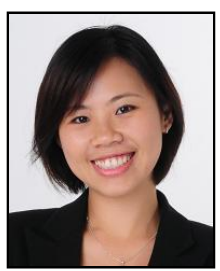

Ms. Jessica Sze Yin HO is currently a lecturer at School of Business, Sunway University, Malaysia. She received her Master of Philosophy in Management and Bachelor of Business Administration majoring in Marketing from Multimedia University, Malaysia (MMU). She is also currently pursuing her $\mathrm{PhD}$ at Multimedia University (MMU). Her research interests include areas in job satisfaction, organizational behavior, service quality, and consumer behavior. Her articles have appeared in International Journal of Business and Management Science; Australian Journal of Basic and Applied Sciences; IEEE International Conference on Industrial Engineering and Engineering Management; and various indexed publications. She is also an associate member of the Malaysia Institute of Management and a member of International Economics Development and Research Centre (IEDRC)

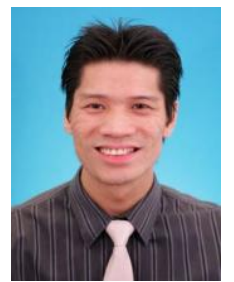

Derek Ong Lai Teik is from Kuala Lumpur born in 1979. He has an Honours Degree in Computer Science from the Science University of Malaysia (2001) and a Master Degree in Applied Statistics in University of Malaya (2002), Malaysia. He is qualified in the field of computer science and applied statistics. He has worked in many education institutions prior to his current engagement. Notably in University of Malaya as a Statistical Computing lecture for 2 years before joining SPSS Malaysia (a Statistics software company based in US) as an Applications Consultant. Currently he is attached to the Sunway University School of Business as a lecturer in the area of Marketing and Statistics. He has published articles in the areas of Data Mining in the Telecommunication, Fitness and the Education sectors. His current interest in research includes education and marketing intelligence. Mr. Derek is currently a life member of the Malaysian Economic Association in which he served as the Honorary Assistant Secretary for 2 years from 2004-2006. He has just been confered. Fellow of the Higher Education Academy (FHEA) and Senior Member Academy of World Business, Marketing and Management Development (SMAWB).

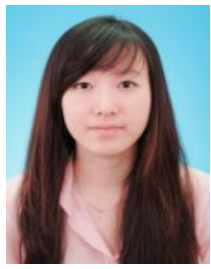

Ms. Felicia Tiffany was born in Indonesia. She is currently a third year student pursuing B. Sc. (Hons) Business Management programme in Sunway University, Malaysia. Her research interests include areas in job satisfaction and marketing (consumer behavior).

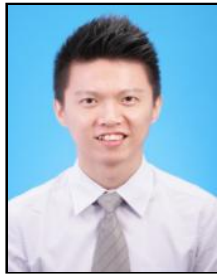

Mr. Tat Yang TEH is currently a final year student in the B. Sc. (Hons.) Business Management, at Sunway University School of Business, Malaysia. He was awarded the "High Achiever Award" for his services as the 'Director of Department of Special Task' in the Sunway University College student Council 2009. His research interests include areas in consumer behavior and marketing.

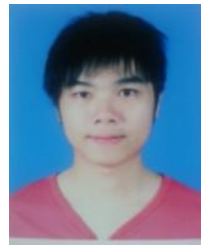

Mr. Loong Fatt KOK is currently a student at School of Business, Sunway University, Malaysia. $\mathrm{He}$ is pursuing his B. Sc. (Hons) Business Management programme from Sunway University. His research interests include areas in service quality and consumer behavior. 